\title{
Effectiveness of Customer Relationship Management on Customer Satisfaction in the Commercial Banks of Taiwan
}

\author{
Hui-I Yao \\ The University of Nottingham, Malaysia Campus \\ E-Mail: sax6hy@nottingham.edu.my \\ Kok Wei Khong \\ The University of Nottingham, Malaysia Campus \\ E-Mail: khong.kokwei@nottingham.edu.my
}

\begin{abstract}
The understanding of how to manage customer relationship effectively has become an important topic for both academics and practitioners in recent years. However, the existing academic literature on customer relationship management (CRM) strategies of banks does not provide a comprehensive outline of what specifically constitutes CRM phases. This study has three purposes: to conceptualize and operationalize the CRM implementation in commercial banks in Taiwan; to determine whether the CRM implementation is positively associated with customer satisfaction; and to determine key moderators between CRM implementation and customer satisfaction. Findings revealed that CRM implementation is associated with customer satisfaction; and there are significant interactions amongst IT capability, contact rate management and recovery management with customer satisfaction. A regression model was churned to evaluate the criteria to measure the level of CRM implementation on customer satisfaction.
\end{abstract}

Keywords: CRM, Commercial Banks, Customer Satisfaction, Organizational Characteristics, and Eigen Value

\section{INTRODUCTION}

In recent years many banks intend to develop and manage stronger interaction with their customers with the aim to maximize customer equity. This involves building and managing successful customer relationships to raise customer 
satisfaction. After 1990s, the number of banking consolidation and cross-sector business increased rapidly. Taiwan's financial industry, which now accounts for $12 \%$ of total GDP, has changed greatly in the past few decades and become a flagship amongst the service industries. Due to the dramatic changes in the global business environment and the shift of power from businesses to customers, the paradigm of Business-to-Customer has been replaced by that of CRM. Inevitably, many banks have begun to rethink on how to build valuable relationships with their customers.

The existing academic literature of CRM strategies of banks does not provide a comprehensive outline of what specifically constitutes CRM phases. The expected contribution of this article is to conceptualize and operationalize a measure to which CRM is implemented in commercial banks in Taiwan. This study has three purposes: (1) to conceptualize and operationalize the CRM implementation in commercial banks in Taiwan; (2) to determine whether the CRM implementation is positively associated with customer satisfaction; and (3) to determine key moderators between the association of CRM implementation and customer satisfaction. The aim of this study is to establish a causal relationship model of CRM in the commercial banks of Taiwan.

\section{THEORETICAL FOUNDATION OF THE CRM IMPLEMENTATION}

The literature on CRM suggests that banks should consider the customer relationship life cycle (Dwyer et al., 1987). This life cycle describes ideal phases that occur regularly in a customer relationship. In general, there are three core phases: Customer Acquisition, Customer Enhancement, and Customer Recovery. CRM implementation is a long term longitudinal phenomena. Thus, in this study, the three core stages are characterized in greater details in terms of the associated attributes of commercial banks in Taiwan.

First, the acquisition phase describes the initiation of a customer-bank relationship. A bank faces the following marketing tasks: customer persuasion and customer stimulation. Quality guarantees are supposed to convince the potential customer (Moorthy and Srinivasan, 1995). In addition, recommendation by other customers, such as using word-of mouth (WOM) communication achieves the same effect (Haywood, 1989). Villanueva et al. (2008) maintain that customers who are acquired via WOM add more long-term value to the firm than customers via traditional marketing channels. Many researchers have pointed out that firms should create WOM communication (Godes and Mayzlin, 2004; Liu, 2006). A stimulation strategy provides customers incentives to enter into a relationship with banks. 
Short-term stimulation serves to generate a single transaction, such as special sales. Long-term stimulation is aimed at multiple transactions and designed to develop a lasting customer relationship. It may include discounts and package deals.

The next stage is the customer enhancement phase. This phase includes three major CRM tasks: contact rate management, regular evaluation management, and increasing selling management. In CRM initiatives, customer representatives help customers get used to the products and services, thereby increase customer familiarity. The representatives also collect customer information. As the service industry has a high degree of integration and interaction in terms of contact contribution, empowerment is a helpful instrument for successful control of individual customer relationships (Mudie and Cottam, 1993). Therefore many banking service systems, such as ATM, Internet banking, and call center play the role of touchpoints. One of the characteristics of successful CRM implementation is the capability of the business to develop better or more suitable products and services via these "touchpoints" (Davenport et al., 2001). The most obvious evidence of these "touchpoints" is the use of Internet which decreases the communication cost with customers (Sharma et al., 2000). Deploying IT support functions fosters one-to-one relationships with each individual customer at any time (Shoemaker, 2001). Profitability of individual customers may change over time. In the CRM paradigm, one of the key goals is to determine different resource allocations for different tiers of customer. The customer's tier membership depends on the economic value of that customer or segment of the business (Zeithaml et al., 2001). A common finding is that businesses overspend on marginal customers and the most profitable customers do not receive their fair share of attention (Reinartz et al., 2004). Businesses systematically attempt to mature relationships by cross-selling products with high purchase likelihood (Kamakura et al., 2002). In the mature phase for instance, when the customer potential has been maximized the business goal is to maintain the sales level by providing up-selling and customized offerings. Sometimes strengthening the customer relationship is unlikely in the maturity stage of the lifecycle. So, banks reinforce the switching barriers. The switching barriers will ensure that a customer is dependent on the banks and that the related turnover and profits are secured.

Third, the termination of a customer relationship usually happens when the customer feels that the value of the service declines. Smith and Bolton (1998) maintain that customers demand and expect service recovery if failures took place. Service recovery is critical as it provides an opportunity to retain customers. If the customer has been lost but is still attractive, recovery offers could be made to the 
customer (e.g. cancellation in the initiation fee; taking care of formality caused by the switching) or value added services could be offered.

In the customer-centered paradigm, customer asset management (CAM), customer equity $(\mathrm{CE})$, return on quality and service profit chain are similar to CRM (Berger et al., 2002; Blattberg et al, 2001; Rust et al., 1995; Heskett et al., 1994). These management concepts are based on customer-centered viewpoints. One of the similarities shared by the above concepts is customer knowledge as the key factor. The ability to obtain customer knowledge is a competitive advantage in the contemporary paradigm (Hogan et al., 2002). Collecting customer data and analysis are the foundation of these management concepts. Moreover, Oliver (1999) found that the key concept, ie customer satisfaction, is a central foundation across all these concepts. However, there are differences between these concepts. The service profit chain and return on quality approaches emphasize on service quality issues while CAM, CE, and CRM on identifying profitable customers and treating them adequately (Reinartz et al., 2004). There are also differences between CAM, CE, and CRM. On the basis of homogenous customer segments, CAM and CE still apply traditional marketing strategies to manage customer assets. Consequently CAM and CE approaches do not break the segments into smaller units. CRM, on the other hand, puts more emphasis on the individual customers, treating them individually on a large scale. So, the CRM perspective centers on individual customer relationships, instead of the segments that are regarded as assets by CAM and CE.

\section{HYPOTHESIS DEVELOPMENT}

In CRM, satisfaction is a customer's cumulative evaluation of the purchase and consumption experience (Anderson et al., 1994). Long-term customers are less sensitive to losses generated from a given transaction because they tend to weigh prior satisfaction levels highly (Bolton, 1998). One of the emphases of CRM is to provide individual customers with customized products and services. Customized offerings are very likely to meet customers' real needs, or to raise the perceived quality of the customer, and subsequently the level of customer satisfaction may rise. Morales (2005) also proposed that relationship marketing investments generate customer feelings of gratitude, which lead to gratitude-based exchange behaviors, resulting in enhanced firm performance. Bolton (1998) noted that firms that have stronger relationships with customers get higher profitability. Thus, CRM do seem to contribute to customer satisfaction.

Many studies have proposed that CRM technology and organizational alignment 
moderate the results of CRM activities and business performance. Deploying IT helps foster one-to-one relationships with each individual customer (Shoemaker, 2001). Furthermore technology facilitates customized offerings at declining prices (Peppers and Rogers, 1997). Therefore consistent service experience is easily delivered to customers through IT tools (Piccoli and Ives, 2005). Contingency theory hypothesizes that business profits will be greater if fitted business structures are developed as well (Miller, 1996). Thus a fitted alignment of organizational structure fosters business performance. Kotler (2002) maintains that a clear organizational mission is the same as an "invisible hand", which states the aim of a firm, and directs the behavior of its employees. Kohli and Jaworski (1990) also maintain that a clear customer-oriented mission can help guide employees' behavior. Therefore, the moderating effect seems clear. In this study, organizational characteristics refer to IT capability, IT investment, and customer-oriented alignment. Consequently the following depicts the hypotheses constructed for this paper.

H1: The greater the degree of CRM implementation, the better the customer satisfaction.

H2a: IT capability has a positive moderating effect on the CRM implementation customer satisfaction link.

H2b: IT investment has a positive moderating effect on the CRM implementation customer satisfaction link.

H2c: Customer-oriented alignment has a positive moderating effect on the CRM implementation - customer satisfaction link.

\section{METHODOLOGY}

This study is based on the causal research design which included both secondary and primary information sources. Primary data was collected from 31 general managers of 42 commercial banks of Taiwan via a questionnaire. The questionnaire incorporated 7 nominal-scaled and 40 five-point interval-scaled questions. Feedback from the pilot test showed that the wording was not easily understood by the respondents. This problem was later rectified and the 40 five-point interval-scaled questions were retained. The improved questionnaires were later sent to the 42 intended respondents by both email and registered post. These 42 intended respondents were selected according to the data presented in the 2009 Financial Statistics Abstract of Taiwan. Once the sampling plan and size were determined, pre-mailing telephone calls were made to the 42 general managers' offices. The author conducted follow-up telephone calls twice a fortnight after the initial sending out of 
questionnaires. The author received 20 mail responses and 11 digital responses. Finally, screening was carried out. Gay (1992) proposed that the respondents should exceed 30 when conducting correlation studies. Altogether, 31 complete responses were collected representing a 73.8\% response rate which was considered satisfactory.

A valid questionnaire must be able to measure the research purpose. The measured items of this research were established according to the relevant literature. Moreover, the questionnaire was pre-tested by experts in the field and then revised in light of the experts' suggestions before being sent out to the respondents. Therefore, the measures of this research have face validity.

\section{RESULTS}

Factor analysis was carried out on the 21 items of the construct, i.e. CRM. Five factors with eigenvalue exceeding 1 were extracted; the cumulative explanation variance of these 5 extracted factors is $80.6 \%$. The individual Cronbach's $\alpha$ of these 5 factors are $0.927,0.868,0.860,0.823$ and 0.865 respectively. The loadings of these five extracted factors are between 0.540 and 0.897 . The composite reliability of the construct, CRM Implementation, is 0.941 . These five extracted factors are labeled as acquisition management, contact rate management, regular evaluation management, increasing selling management, and recovery management. Another factor analysis was carried out on 9 items of the construct, i.e. organizational characteristics. Three factors with eigenvalue exceeding 1 were extracted; the cumulative explanation variance of these three extracted factors is 79\%. The individual Cronbach's $\alpha$ of these three extracted factors are $0.789,0.831$, and 0.827 respectively. The loadings of these three factors are between 0.666 and 0.905 . The composite reliability of the construct, organizational characteristics, is 0.831 . These three extracted factors are named IT capability, IT investment, and customer-oriented alignment. Then the final factor analysis was carried out on 10 items of the construct, i.e. customer satisfaction. Two factors with eigenvalue exceeding 1 were extracted; the cumulative explanation variance of these two extracted factors is $65 \%$. The individual Cronbach's $\alpha$ of these two factors are 0.864 , and 0.802 respectively. The loadings of these two extracted factors are between 0.594 and 0.869 . The composite reliability the construct, customer satisfaction, is 0.846. These two extracted factors are named cross-selling and willing-to-pay. To sum up, the reliability of each construct is acceptable.

When conducting regression analysis, variables are grouped into main effects, standardized coefficients $(\beta \mathrm{s})$, and interaction effects $(\gamma \mathrm{s})$. All estimations fit the data well where the $\mathrm{R}^{2}$ is 0.420 for cross-selling and 0.809 for willing-to-pay. 
This study hypothesized that the degree of CRM implementation is positively associated with Customer Satisfaction (H1). There are five factors extracted from the CRM dimension. Meanwhile two factors extracted from customer satisfaction, i.e. cross-selling and willing-to-pay, are dependent variables. Support is the strongest for increasing selling management $(\beta=0.658, \mathrm{p}=0.000)$, acquisition management $(\beta=$ 0.375 , accumulative $p=0.000)$, and regular evaluation management $(\beta=0.375$, accumulative $\mathrm{p}=0.000$ ) in willing-to-pay. The association between recovery management and willing-to-pay is negative but marginal $(\beta=-0.309$, accumulative $p=$ $0.000)$. Support is the strongest for contact rate management $(\beta=0.532, \mathrm{p}=0.002)$ but marginal for recovery management $(\beta=0.370$, accumulative $\mathrm{p}=0.000)$ in cross-selling. Thus, the more banks engage in CRM implementation, the better the customer satisfaction is. To sum up, $\mathrm{H} 1$ is accepted.

The next study hypothesized that IT capability has a positive moderating effect on the CRM implementation - customer satisfaction link. (H2a). For cross-selling, IT capability is marginally supporting contact rate management $(\gamma=0.412, \mathrm{p}<0.05)$ and recovery management $(\gamma=0.365, \mathrm{p}<0.05)$. This means that the interaction between contact rate management and IT capability $(\gamma=0.412, \mathrm{p}<0.05)$ is positively associated with cross-selling. Additionally, the interaction between recovery management and IT capability $(\gamma=0.365, \mathrm{p}<0.05)$ is also positively associated with cross-selling. Finally for willing-to-pay, the moderating effect of IT capability was not significant in any CRM sub-constructs. To sum up, $\mathrm{H} 2 \mathrm{a}$ is accepted.

In testing $\mathrm{H} 2 \mathrm{~b}, \mathrm{IT}$ investment has a positive moderating effect on the CRM implementation - customer satisfaction link. Notably, this finding was somewhat contrary to the literature. The interactions between IT investment and each CRM implementation activity were not significant. Thus, $\mathrm{H} 2 \mathrm{~b}$ was not significant for any sub-constructs of customer satisfaction. To sum up, H2b is not supported.

The final study hypothesized that customer-oriented alignment has a positive moderating effect on the CRM implementation - customer satisfaction link $(\mathrm{H} 2 \mathrm{c})$. Similar to $\mathrm{H} 2 \mathrm{~b}$ the finding was contrary to the literature. The interactions between customer-oriented alignment and each CRM implementation activity were not significant. Thus, H2c was not significant for any sub-constructs of customer satisfaction. Consequently, H2c is not supported.

\section{FINDINGS}

The results of this empirical study produced the following notable findings. First, this study presented the most relevant and fundamental theoretical approaches that 
form the basis of conceptualizing CRM in the investigated industry, i.e. banking (see Table 1 for instruments of CRM implementation). In essence, this paper contributes to the existing knowledge in CRM. Second, the implementation of CRM is positively associated with customer satisfaction. Third, there is a significant interaction between IT capability and both contact rate management and recovery management in the context of improving customer satisfaction. Fourth, the moderating effect of IT investment is not significant. Lastly, the moderating effect of customized-oriented alignment is not significant.

Table 1 Overview of Phase-Driven CRM Instruments

\begin{tabular}{|c|c|c|}
\hline Phases & Tasks & Instruments \\
\hline \multirow{2}{*}{ Acquisition } & Customer Persuasion & $\begin{array}{l}\text { * Quality guarantee } \\
\text { * Recommendation }\end{array}$ \\
\hline & Customer Stimulation & $\begin{array}{l}* \text { Short-term stimulation } \\
* \text { Long-term stimulation }\end{array}$ \\
\hline \multirow{3}{*}{ Enhancement } & Contact Rate & $\begin{array}{l}\text { * Frequency of personal contact } \\
\text { * Perceived exchange quality } \\
\text { * Empowerment } \\
\text { * Multiple contact channels }\end{array}$ \\
\hline & Regular Evaluation & * Regular evaluation on profitability \\
\hline & Increasing Selling & $\begin{array}{l}* \text { Cross-selling } \\
* \text { Up-Selling } \\
* \text { Customized Offering } \\
* \text { Setting up switching barriers } \\
* \text { Lower service costs }\end{array}$ \\
\hline Recovery & Recovery & $\begin{array}{l}* \text { Error rectification in } 4 \mathrm{P} \text { and service } \\
* \text { Recovery offers in } 4 \mathrm{P} \text { and service } \\
* \text { Added value in } 4 \mathrm{P} \text { and customized service }\end{array}$ \\
\hline
\end{tabular}

\section{DISCUSSION}

This study provides a systematic outline of CRM initiatives that take place at each phase. Thus, this model can be adapted to identify the key success factors in CRM, and can be an evaluation criterion to measure the level of CRM implementation. The findings indicate that the implementation of CRM is positively associated with customer satisfaction. The strongest positive effect is via acquisition management, regular evaluation management, and increasing selling management, followed by contact rate management and recovery management. Notably, the support of recovery management (although is negatively associated with willing-to-pay) is only marginally.

In the case of recovery management, two possible explanations exist in this result. 
Customer recovery management was underestimated by banks so they did not implement it effectively. In addition banks may be subject to type II error which means that they are probably reluctant to revive a relationship of lost customers, who they defined perhaps carelessly, as unprofitable (Yao and Khong, 2008). There is a significant interaction between IT capability and both contact rate management and recovery management in the context of cross-selling. Thus, implementation of CRM is more likely to raise customer satisfaction as banks develop technology systems that can support CRM activities.

Another notable finding in the results shows that technology investments do not perform up to expectations. As a result, the moderating effects of IT investment were not significant. This finding implies that there are difficulties in making an IT investment pay off. However, it also can be argued that technology investment offers positive benefits only if initial implementation difficulties are overcame. CRM information technology investment is relatively recent, so the benefits generated from it are still not obvious. This result shows that successful implementation of CRM is not synonymous to technology development. Thus, if banks only concentrate on technological aspects when implementing CRM, the companies are more likely to be disappointed. For example, as banks started to use technology to shift from personal customer interaction to Internet or call-center-based interactions, many customers experienced a drop in the quality of the communication process. This is a waste of resources.

The last finding suggests that the moderating effect of customized-oriented alignment is not significant. This result echoes the previous finding implying that empowerment can be an additional helpful instrument in CRM for successful control of individual relationships (Mudie and Cottam, 1993). The most important role in contacting specific customers and making the regular evaluation and segmentation is that of the customer representatives. Thus one can expect empowerment is more critical than teamwork. Another possible explanation is that the customer base within the bank becomes unstable if customer-centric alignment is emphasized. This is why more initiatives are adopted to satisfy the customer base. One of the most important goals of CRM implementation is to obtain and maintain a stable customer base, which leads to efficient allocation of resources. As the bank lacks a stable customer base, one can expect it to practice forced alignment. This result seems to reflect that an unstable customer base exists. 


\section{MANAGERIAL IMPLICATIONS}

The findings of this study show the following implications in commercial banks in Taiwan. First, this study provides a comprehensive as well as a systematic outline of the CRM initiatives that take place at each phase. Second, the result indicates that CRM-customer satisfaction link is strong as suggested in the literature. The findings also indicate that recovery management in profitable lost customers was underestimated implying that banks do not implement recovery activities effectively. Third, the result indicates that the moderator effects are not as strong as expected. CRM implementation is likely to raise customer satisfaction as banks develop technology systems to support communication. Customer representatives play the most important role in communicating with customers. Thus this result echoes the conclusion that empowerment rather than teamwork is recommended for customer-oriented design.

There were some limitations in this research. Although ample research was carried out the concept of CRM continues to evolve constantly. Consequently longitudinal research could be carried out to enrich the present proposed model. For instance, the negative effect or return of IT investment at present may possibly revert to a positive effect over time. This means pay off from IT investment may be realized in the long run. In any surveys carried out, common method variance may exist to some extent. Thus, the bias of the correlation among variables may probably be present. Nevertheless internal consistencies were conducted to overcome this problem.

\section{REFERENCES}

Anderson, E. W., Fornell, C., \& Lehmann, D. (1994). Customer Satisfaction, Market Share, and Profitability: Findings From Sweden. Journal of Marketing, 58(3), 53-66.

Berger, P. D., Bolton, R. N., Bowman, D., Briggs, E., Kumar, V., Parasuraman, A., \& Creed, T. (2002). Marketing Actions and the Value of Customer Assets. Journal of Service Research, 5(1), 39-54.

Blattberg, R. C., Getz, G., \& Thomas, J. S. (2001). Customer Equity: Building and Managing Relationships as Valuable Assets. Boston: Harvard Business School Press.

Bolton, R. N. (1998). A Dynamic Model of the Duration of the Customer's Relationship with a Continuous Service Provider: The Role of Satisfaction. Journal of Marketing Science, 17(1), 45-65. 
Davenport, T. H., Harris, J. G., \& Kohli, A. K. (2001). How Do They Know Their Customers So Well? Sloan Management Review, 42(2), 63-73.

Dwyer, F. R., Schurr, P. H., \& Oh, S. (1987). Developing Buyer-Seller Relations. Journal of Marketing, 51(2), 11-28.

Gay, L. R. (1992). Educational Research Competencies for Analysis and Application. New York: Macmillan.

Godes, D. \& Mayzlin, D. (2004). Using Online Conversations to Study Word-of Mouth Communication. Journal of Marketing Science, 23(4), 545-560.

Haywood, K. M. (1989). Managing Word of Mouth Communications. Journal of Services Marketing, 3(2), 55-67.

Heskett, J. L., Jones, T. O., Loveman, G., Sasser, W. E., Jr., \& Schlesinger, L. A. (1994). Putting the Service-Profit Chain to Work. Harvard Business Review, 72(2), 164-170.

Hogan, J. E., Lemon, K. N., \& Rust, R. T. (2002). Customer Equity Management: Charting New Directions for Future of Marketing. Journal of Service Research, 5(1), 4-12.

Kamakura, W. A., Mittal, V., de Rosa, F., \& Mazzon, J. A. (2002). Assessing the Service Profit Chain. Journal of Marketing Science, 21(3), 294-317.

Kohli, A. \& Jaworski. B. (1990). Market Orientation: The Construct, Research Propositions, and Managerial Implications. Journal of Marketing, 54(2), 1-18.

Kotler, P. \& Armstrong, G. (2002). Principles of Marketing (9 ${ }^{\text {th }}$ ed.). Taipei: Tung-Hwa.

Liu, Y. (2006). Word-of Mouth for movies: Its Dynamic and Impact on Box Office Revenue. Journal of Marketing, 70(3), 74-89.

Miller, D. (1996). Configuration Revisited. Journal of Strategic Management, 17(1), 505-512.

Moorthy, S. \& Srinivasan, K. (1995). Signaling Quality with a Money-Back Guarantee: The Role of Transaction Costs. Journal of Marketing Science, 14(4), 442-446.

Morales, A. C. (2005). Giving Firms an "E" for Effort: Consumer Responses to High-Effort Firms. Journal of Consumer Research, 31(4), 806-812.

Mudie, P. \& Cottam, A. (1993). The Management and Marketing of Services. Oxford: Butterworth-Heinemann.

Oliver, R. L. (1999). Whence Consumer Loyalty? Journal of Marketing, 63(4), 33-44.

Peppers, D. \& Rogers. M. (1997). Enterprise One to One: Tools for Competing in the Interactive Age. New York: Doubleday. 
Piccoli, G. \& Ives, B. (2005). IT-dependent Strategic Initiatives and Sustained Competitive Advantage: A Review and Synthesis of the Literature. MIS Quarterly, 29(4), 747-776.

Reinartz, W., Krafft, M., \& Hoyer, W. D. (2004). The CRM Process: Its Measurement and Impact on Performance. Journal of Marketing Research, 41(3), 293-305.

Rust, R. T., Zahorik, A. J., \& Keiningham. T. L. (1995). Return on Quality (ROQ): Making Service Quality Financially Accountable. Journal of Marketing, 59(2), 58-70.

Sharma, A., Levy, M., \& Kumar, A. (2000). Knowledge Structures of Salespeople as Antecedents of Retail Sales Performance: An Empirical Examination. Journal of Retailing, 76(1), 53-69.

Shoemaker, M. E. (2001). A Framework for Examining IT-Enabled Market Relationships. Personal Selling \& Sales Management, 21(2), 177-186.

Smith, A. K. \& Bolton, R. N. (1998). An Experimental Investigation of Customer Reactions to Service Failure and Recovery Encounters: Paradox or Peril? Journal of Service Research, 1(1), 65-81.

Villanueva, J., Yoo, S., \& Hanssens, D. M. (2008). The Impact of Marketing-Induced vs. Word-of-Mouth Customer Acquisition on Customer Equity Growth. Journal of Marketing Research, 45(1), 48-59.

Yao, H. I. \& Khong, K. W. (2008, June). Effectiveness of CRM on Customer Satisfaction and Performance in the Internet Banking of Taiwan. The 30th Annual Marketing Science Conference of The Institute of Operations Research and Management Sciences, University of British Columbia, Canada.

Zeithaml, V. A., Rust, R. T., \& Lemon, K. N. (2001). The Customer Pyramid: Creating and Serving Profitable Customers. California Management Review, 43(4), 118-142. 